\title{
Analysis of Factors Affecting Free Surface Vortex Formation during Steel Teeming
}

\author{
Hong-Xia LI, ${ }^{1)}$ Qiang WANG, ${ }^{1,2) *}$ Jia-Wei JIANG, ${ }^{1)}$ Hong LEI, ${ }^{1)}$ Zhan-Cheng GUO ${ }^{2)}$ and Ji-Cheng HE ${ }^{1)}$ \\ 1) Key Laboratory of Electromagnetic Processing of Materials (Ministry of Education), Northeastern University, Heping \\ District, Shenyang City, 110819 China. $\quad$ 2) State Key Laboratory of Advanced Metallurgy, University of Science and \\ Technology Beijing, Haidian District, Beijing City, 100083 China.
}

(Received on February 20, 2015; accepted on September 29, 2015)

\begin{abstract}
To suppress slag entrapment by vortexes during steel teeming, and to improve steel cleanliness, key factors affecting free surface vortex formation have been analyzed in this study. It was found that Coriolis forces have little effect on vortex formation. The initial tangential disturbance is the main factor for vortex formation. And when the nozzle position is central or eccentric, the effects of initial tangential velocity, nozzle diameter on the critical height are different. Physical properties of liquid steel have a small effect on the critical height. A formula for calculating the height was discussed.
\end{abstract}

KEY WORDS: clean steel; inclusions; vortex; steel teeming.

\section{Introduction}

Reducing inclusions and further implementing some improvements in steel quality are of considerable interest to the steel industry. During steel teeming, vortexes can form above the nozzle as the liquid level of the molten steel decreases. A vortex results in inhibiting inclusion floatation and entrapping slag and air, causing nozzle corrosion and clogging, and increasing molten steel reoxidation. All of these problems seriously affect the quality of steels. ${ }^{1,2)}$ However, in order to reduce the effects of vortexes, residual molten steel often remains in the ladle. For example, up to $3 \mathrm{t}$ of steel can be left in a ladle with a of diameter $2-3 \mathrm{~m}$, a height of $3 \mathrm{~m}$, and a nozzle diameter of 5-10 $\mathrm{cm}$, and initially $100-200 \mathrm{t}$ of molten steel. ${ }^{3)}$ Thus, understanding the principles of free-surface vortex formation, and how to inhibit formation and evolution during steel teeming, are critical issues from economic and quality perspectives.

Free-surface vortex formation during steel teeming has been studied via water models, such as a vortex in a tub. Andrade $^{4}$ proposed that vortex motion followed the principle of conservation of angular momentum, where the angular velocity of water circulating around an axis has to increase as the distance from the axis decreases. Because there is angular velocity (tangential velocity) in a fluid flowing out of a nozzle, a rotational vortexing funnel will form. In the absence of angular velocity, non-vortexing funnels will eventually form. Many researchers thought that it was caused by the rotational Coriolis force from the earth's rotation. Shapiro ${ }^{5)}$ confirmed experimentally that vortexes in the northern hemisphere rotated counterclockwise, while Trefethen et $a l .{ }^{6}$ ) confirmed that they rotated clockwise in

\footnotetext{
* Corresponding author: E-mail: wangq@mail.neu.edu.cn DOI: http://dx.doi.org/10.2355/isijinternational.ISIJINT-2015-096
}

the southern hemisphere. However, Haugen et al. ${ }^{7)}$ reported that this effect was not significant for small-scale vortexes, and that both directions were possible in the northern hemisphere. Suh et al. ${ }^{8)}$ pointed out that Coriolis forces could be neglected under normal flow conditions, except when the fluid had completely settled over a long period of time.

In addition, many researchers have examined the factors important to the vortex formation. Lin et al. ${ }^{9)}$ pointed out that the rotary direction was uncertain when there was no resting time, but that vortexes rotated anticlockwise with prolonged resting times. With increased nozzle eccentricity (eccentricity is the ratio of the nozzle distance and the ladle radius), the vortex deviates from the nozzle, and its rotary direction becomes random. Hammerschmid et al. ${ }^{10)}$ found that the critical height (The critical height is the distance from the liquid level to the upper surface of the nozzle when the tip of vortex arrives to top edge of the nozzle) decreased with increasing resting time, and was proportional to the initial rotational velocity of the fluid. In contrast, Morales et al. ${ }^{11)}$ pointed out that residual motion had little effect on the critical height when the fluid was stirred at a constant speed. For water models, Lin et al. ${ }^{12)}$ reported that the critical height increased with increasing nozzle diameter. Sankaranarayanan and Guthrie ${ }^{13)}$ pointed out that the critical height was proportional to the ratio of the nozzle diameter to the ladle diameter, and that it increased with increased initial liquid level when the ratio was constant. But Lin et al. ${ }^{12)}$ and Huang et $a l .{ }^{14)}$ found that the initial liquid level had little effect on the vortex critical height. Lin et al. ${ }^{12)}$ and Sucker et al. ${ }^{15)}$ reported that the critical height decreased with increasing nozzle eccentricity.

Many researchers have also examined vortex formation through numerical simulation. Zhao et al. ${ }^{16)}$ obtained the structure and movement of free-surface vortexes using a multiphase volume-of-fluid (VOF) model. They reported 
that external disturbances, asymmetric geometry, and surface roughness led to tangential fluid flow. The tangential flowing created vortex with random rotary directions in a tub that is similar to the Rankine vortex. Kuwana et al. ${ }^{17)}$ simulated water models using computational fluid dynamics (CFD) and found that vortex formation was dependent on the initial tangential velocity. They developed a relation for the critical height using Froude and Reynolds numbers. Davila et al. ${ }^{18)}$ and Morales et al. ${ }^{11)}$ used a VOF model to simulate steel teeming under insulated and non-insulated thermal conditions. They reported that the height of vortex formation increased because of the buoyancy caused by temperature gradients.

Despite all the previous researches, vortex formation is still not very well understood. A free-surface vortex in a ladle during steel teeming involves extremely complex fluid movement that has not been characterized in detail. Previously, we studied a free-surface vortex during steel teeming and analyzed its formation. ${ }^{19)}$ Here, various factors determining vortex formation are analyzed and vortex motions under different conditions are described in detail. A vortex critical height formula is derived from which critical heights are calculated and verified by the experiments by the other researchers. This work thus provides a theoretical basis for vortex prevention.

\section{Numerical Solution}

Free-surface vortex formation during steel teeming is simulated by Fluent software. The VOF multiphase model and renormalization-group $k-\varepsilon$ model are used in the simulation. The "finite-volume implicit algorithm" and "pressureimplicit with splitting of operators" algorithms are used. Fluid teeming is simulated with an unsteady state and a 0.01 s time step. The inlet boundary is a pressure inlet and the exit boundary is a pressure outlet. The UDF (User Defined Function) program sets the initial velocity and Coriolis force. The mathematical model for fluid flow in a ladle is based on the following assumptions: the fluid is viscous and incompressible; the effect of temperature is negligible; to simplify modeling, the ladle is assumed cylindrical; the wall thickness of the ladle is neglected; a no-slip condition (zero velocity) for fluid flow near the ladle wall is assumed; and the slag layer on top of the molten steel is neglected. The ladle dimensions are set as reported previously. ${ }^{19)}$ The ladle diameter is $1.16 \mathrm{~m}$, the nozzle diameter is $0.0765 \mathrm{~m}$, the nozzle length is $0.1235 \mathrm{~m}$, and the initial liquid level is $0.5 \mathrm{~m}$.

We analyze the determining factors of vortex formation by altering the nozzle position and diameter. The onset of the vortex formation is determined by visual sense. By simulating the teeming processes for different fluids, the influence of physical properties of molten steel on vortex formation can be studied. The physical parameters of the fluids are listed in Table 1. The simulation method has been verified. ${ }^{19)}$

\section{Factors Affecting Vortex Formation}

\subsection{Effects of Coriolis Forces}

The Coriolis force can cause a deflection of the moving objects when they are viewed in a rotating reference frame. In a reference frame with clockwise rotation, the deflection of the moving objects is to the left; in one with counterclockwise rotation, the deflection is to the right.

The expression of Coriolis force is given by Eq. (1) as follows:

$$
F=2 m \vec{v} \times \vec{\omega}
$$

where $m$ is the fluid particle mass, $\vec{v}$ is of the fluid particle velocity relative to the rotating reference frame, and $\vec{w}$ is the angular velocity of the rotating reference frame (rotational angular velocity of the earth). In order to study the Coriolis effect on the molten steel, the UDF programmer has been successfully applied in this study. The Coriolis force is applied to the molten steel and the upper air respectively. The initial states of lower molten steel and upper air are the same. However, in order to understand the Coriolis effect on the molten steel more clearly, the Coriolis force acting on the air is enlarged by 7000 times than the actual Coriolis force.

Steel teeming under the following different initial conditions is simulated by Fluent simulation software: (1) molten steel outflows naturally; (2) the transport velocity of the ladle in the horizontal $\mathrm{x}$ direction $u_{x}$ is $0.017 \mathrm{~m} / \mathrm{s}$, or (3) 0.33 $\mathrm{m} / \mathrm{s}$; (4) the velocity of the ladle rotating anticlockwise, or (5) clockwise, with respect to the rotational angular velocity of ladle turret $w_{\theta}$ is $0.105 \mathrm{rad} / \mathrm{s}$. The initial liquid level $H_{0}=0.5 \mathrm{~m}$, the nozzle diameter is $0.0765 \mathrm{~m}$, and the nozzle eccentricity is 0.5 in the above five cases. The eccentricity is the ratio of the nozzle distance (from the nozzle center to the ladle center) and the ladle radius. For example, when the nozzle is located in the center of ladle bottom, the eccentricity is 0 ; when at $1 / 2$ the ladle bottom radius, the eccentricity is 0.5 ; or when at $3 / 4$ the ladle bottom radius,

Table 1. Physical parameters of fluids.

\begin{tabular}{|c|c|c|}
\hline Fluid & Parameter & Value \\
\hline \multirow{3}{*}{ Steel } & Density $\left(\mathrm{kg} / \mathrm{m}^{3}\right)$ & 7000 \\
\hline & Dynamic viscosity $(\mathrm{Pa} \cdot \mathrm{s})$ & 0.0053 \\
\hline & Surface tension (N/m) & 1.6 \\
\hline \multirow{3}{*}{ Water } & Density $\left(\mathrm{kg} / \mathrm{m}^{3}\right)$ & 998.2 \\
\hline & Dynamic viscosity $(\mathrm{Pa} \cdot \mathrm{s})$ & 0.001003 \\
\hline & Surface tension (N/m) & 0.0728 \\
\hline \multirow{3}{*}{ Glycerol } & Density $\left(\mathrm{kg} / \mathrm{m}^{3}\right)$ & 1260 \\
\hline & Dynamic viscosity $(\mathrm{Pa} \cdot \mathrm{s})$ & 1.5 \\
\hline & Surface tension $(\mathrm{N} / \mathrm{m})$ & 0.0633 \\
\hline \multirow{3}{*}{ Petrol } & Density $\left(\mathrm{kg} / \mathrm{m}^{3}\right)$ & 680 \\
\hline & Dynamic viscosity $(\mathrm{Pa} \cdot \mathrm{s})$ & 0.00031 \\
\hline & Surface tension $(\mathrm{N} / \mathrm{m})$ & 0.022 \\
\hline \multirow{3}{*}{ Mercury } & Density $\left(\mathrm{kg} / \mathrm{m}^{3}\right)$ & 13600 \\
\hline & Dynamic viscosity $(\mathrm{Pa} \cdot \mathrm{s})$ & 0.00157 \\
\hline & Surface tension $(\mathrm{N} / \mathrm{m})$ & 0.484 \\
\hline Steel & Temperature (K) & 1873 \\
\hline Others & Temperature (K) & 293 \\
\hline
\end{tabular}


the eccentricity is 0.75 . The transport velocity of the ladle and angular velocity of ladle turret are set according to the velocity range in practice. ${ }^{20)}$ The effect of Coriolis force in the northern hemisphere is studied. The simulation results are as follows.

Figure 1(a) shows molten steel that has not begun rotational flow when there is no initial disturbance, but the upper air has rotated anticlockwise for the same conditions. Figures 1(b) and 1(c) show that the molten steel still has not begun rotational flow from an initial horizontal disturbance, but that the upper air has rotated anticlockwise. Figures 1(d) and 1(e) show that when molten steel rotates anticlockwise or clockwise with the rotational ladle turret before steel teeming, it can form a rotational vortex during teeming. The direction of this rotational vortex is consistent with the initial rotational direction of the ladle turret. However, the upper air still rotates anticlockwise because of the Coriolis force. That is because the rotation from ladle turret provided a rotational inertia force. The inertia force drives the molten steel to rotate at the beginning of steel teeming. According to the principle of conservation of angular momentum, the angular velocity of molten steel can increase as the
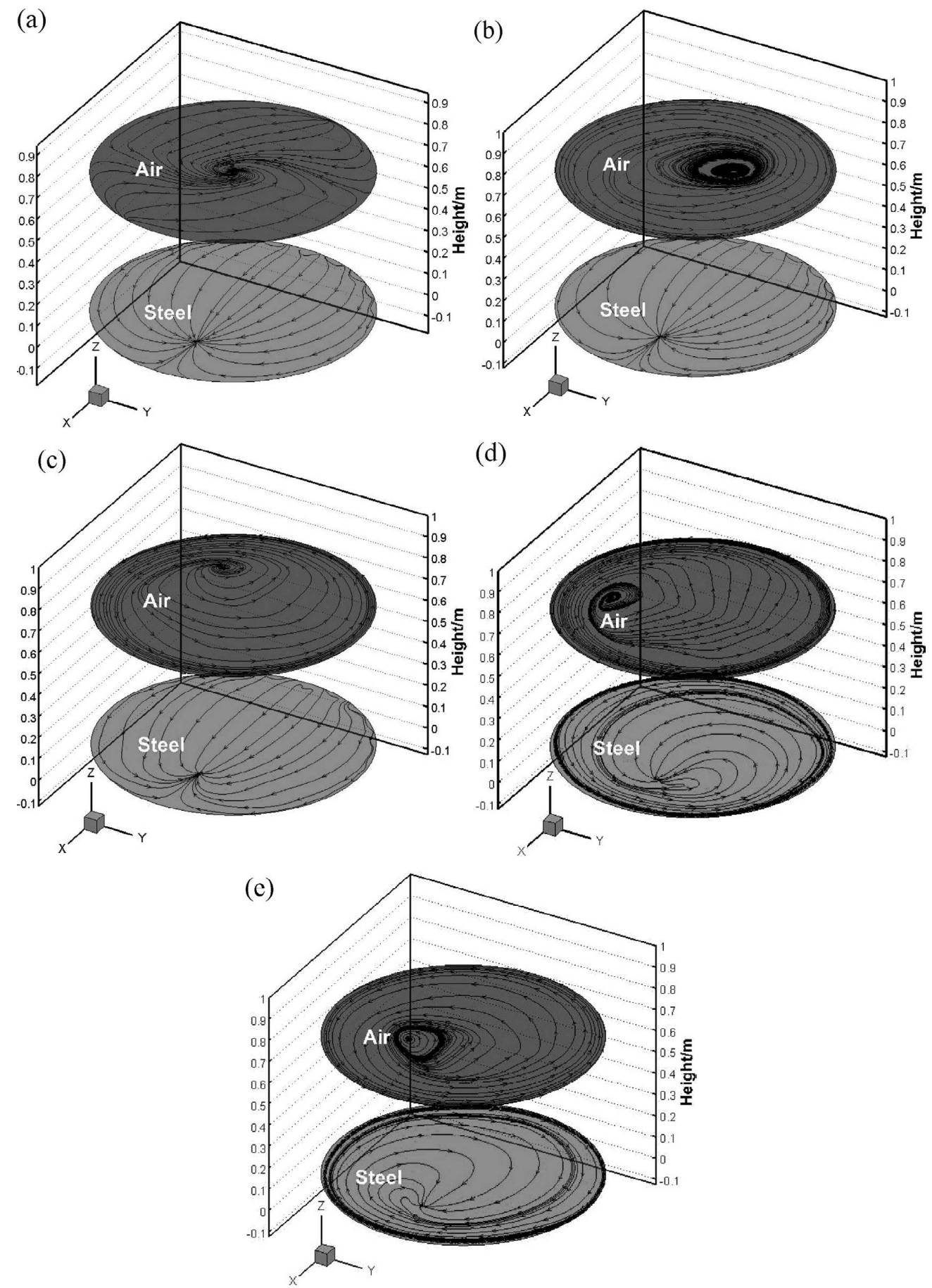

Fig. 1. Stream diagram of molten steel at $0.05 \mathrm{~m}$ and air at $0.7 \mathrm{~m}$ at $30 \mathrm{~s}$ : (a) natural outflow (without any disturbance); (b) when the transport velocity of the ladle is $0.017 \mathrm{~m} / \mathrm{s}$ in horizontal $\mathrm{x}$ direction; (c) when the transport velocity of the ladle is $0.33 \mathrm{~m} / \mathrm{s}$ in horizontal $\mathrm{x}$ direction; (d) when the anticlockwise rotational angular velocity of ladle turret is $0.105 \mathrm{rad} / \mathrm{s}$; (e) when the clockwise rotational angular velocity of ladle turret is $0.105 \mathrm{rad} / \mathrm{s}$. 
fluid flows towards the nozzle. And the gravity provides the enough energy to rotate rapidly, thus the vortex funnel forms gradually as the liquid level decreases. But the rotational vortex will not form as liquid level decreases if there is no rotational motion in molten steel at the beginning of steel teeming, such as the molten steel in Figs. 1(a), 1(b) and 1(c). It is found that the effect of Coriolis force is large on air because the force on the air is enlarged by 7000 times than the actual Coriolis force, which equals to that the velocity of the air is enlarged. However, the Coriolis effect on molten steel is small because of the small velocity during steel teeming. Therefore, it can be concluded that the effect of Coriolis becomes obvious only when the velocity is large enough.

During steel teeming, the liquid level of the molten steel decreases continuously. At a certain time, the surface firstly dimples, which can be considered as the vortex initiation. And then the vortex runs through the nozzle gradually. The critical height is defined as the liquid level when the vortex extends to the nozzle. When the liquid steel level is below the critical height, slag and even air will be strongly entrapped into the tundish. In Fig. 2, molten steel has not begun rotational flow either in the absence of an initial disturbance or with an initial horizontal disturbance only. But the liquid surface still dimples and forms a funnel during steel teeming. The height of the non-rotational funnel extends to the nozzle, which indicates that the critical height is low and that the time that the funnel extends to the nozzle is prolonged. However, during steel teeming, a rotational vortex occurs with an initial tangential movement because of the rotational inertial force provided by ladle turret. The vortex critical height extending to the nozzle is high, and the time is short. In summary, the Coriolis force has little effect on the critical height, but the tangential disturbance has a large effect.

\subsection{Effect of Nozzle Position on Vortex Formation}

The eccentricities were set as $0,0.5$ and 0.75 respectively. The nozzle diameter is $0.0765 \mathrm{~m}$, the initial liquid level $\mathrm{H}_{0}=0.5 \mathrm{~m}$, and the initial tangential velocity $\mathrm{u}_{\theta}=0.06$ $\mathrm{m} / \mathrm{s}$, which corresponds to the rotational angular velocity of ladle turret $\mathrm{w}_{\theta}=0.105 \mathrm{rad} / \mathrm{s}$. Molten steel initially rotates anticlockwise around the center of ladle. The teeming simulation results are as follows.

Figure 3 shows that with increasing eccentricity, the vortex critical height decreases, while the time that the vortex extends to the nozzle increases. For example, the critical height is $0.13 \mathrm{~m}$ when the eccentricity is 0.5 , and $0.07 \mathrm{~m}$ when the eccentricity is 0.75 .

Figure 4 displays the process of free-surface vortex movement. In Fig. 4(a), the center of the vortex is always in the center of the nozzle when the eccentricity is 0. In Figs. 4(b) and 4(c), the center of vortex moves towards the nozzle center gradually. In fact, the movement process of vortex is the fluid rotating itself around central axis of vortex and meanwhile the center of vortex completes revolution around ladle center. But finally the axis of vortex and its revolution center both move to the nozzle because of the fluid flowing out of the nozzle. Then the vortex runs through the nozzle. The eccentricity determines the development and movement of the vortex. In addition, the time it takes for the vortex center to move towards the nozzle is prolonged with increasing eccentricity, so the critical height decreases.

In Fig. 5, the tangential velocity is characterized by the maximum tangential velocity in $0.05 \mathrm{~m}$ plane from the bottom. The tangential velocity increases continuously when

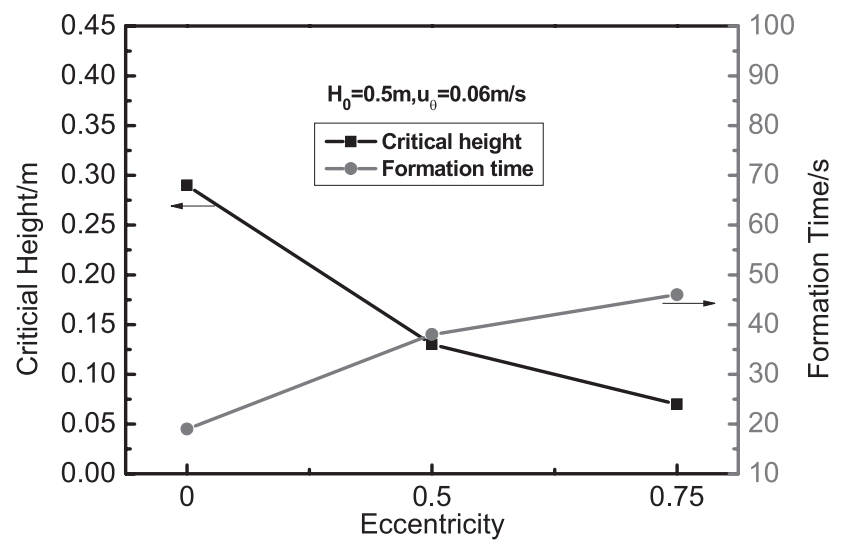

Fig. 3. Vortex critical height and formation time vs. eccentricity.

(a)

(b)
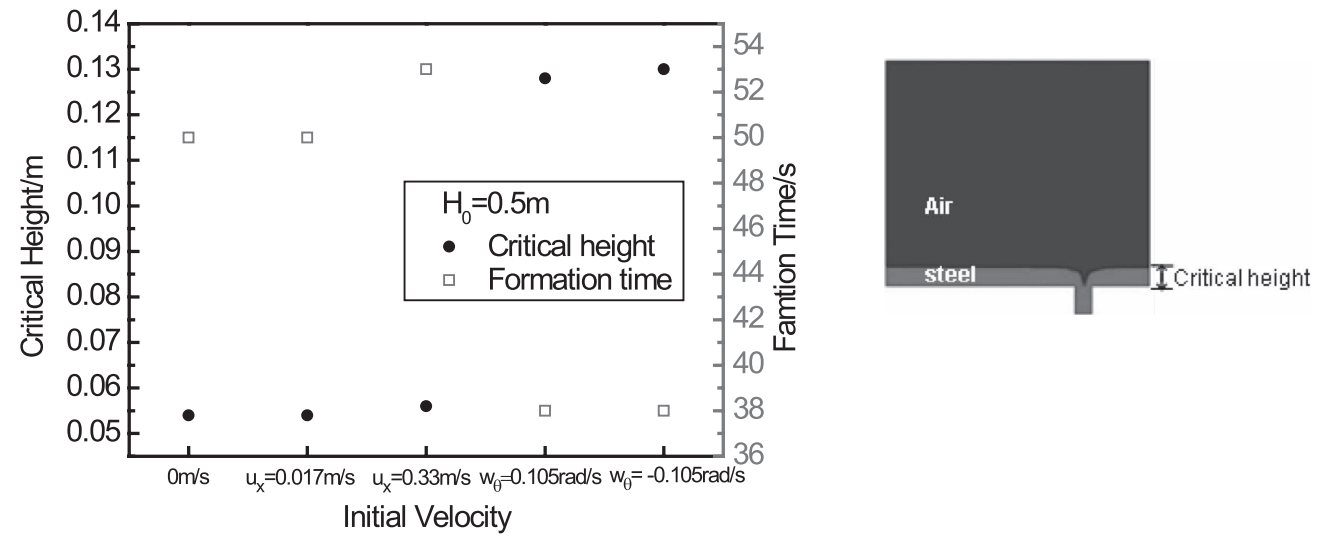

Fig. 2. Critical height and formation time: (a) critical height of vortex and formation time vs. initial disturbance: $H_{0}$, initial liquid level; $u_{x}$, transport velocity in $\mathrm{x}$ direction; $w_{\theta}$, rotational angular velocity (anticlockwise + , clockwise -) and (b) schematic diagram of critical height of vortex extended to nozzle in the ladle. 
(a)

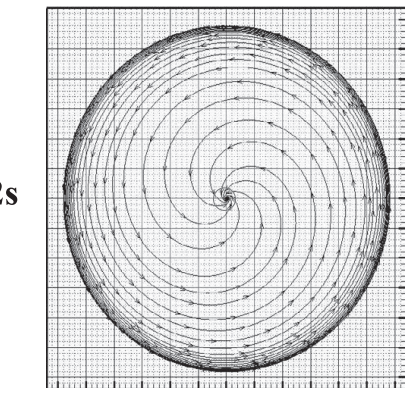

$5 s$

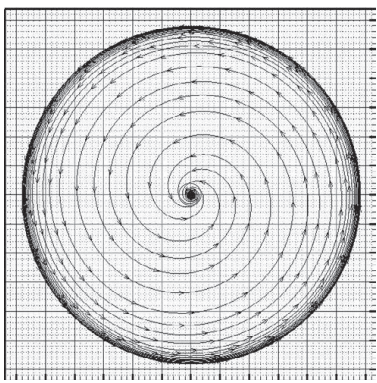

10s

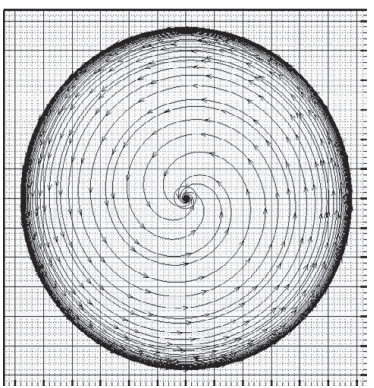

20s

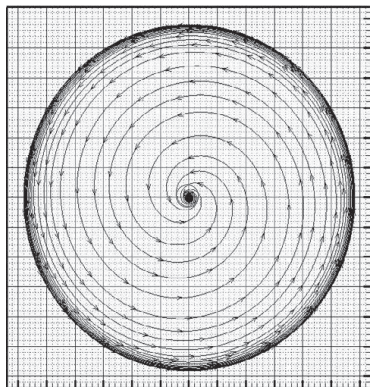

(b)
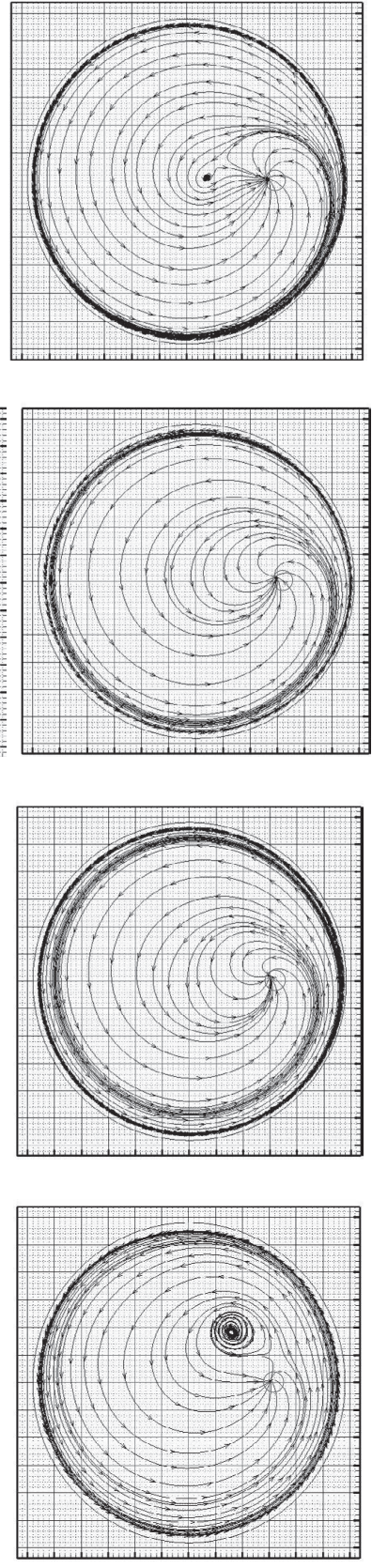

(c)
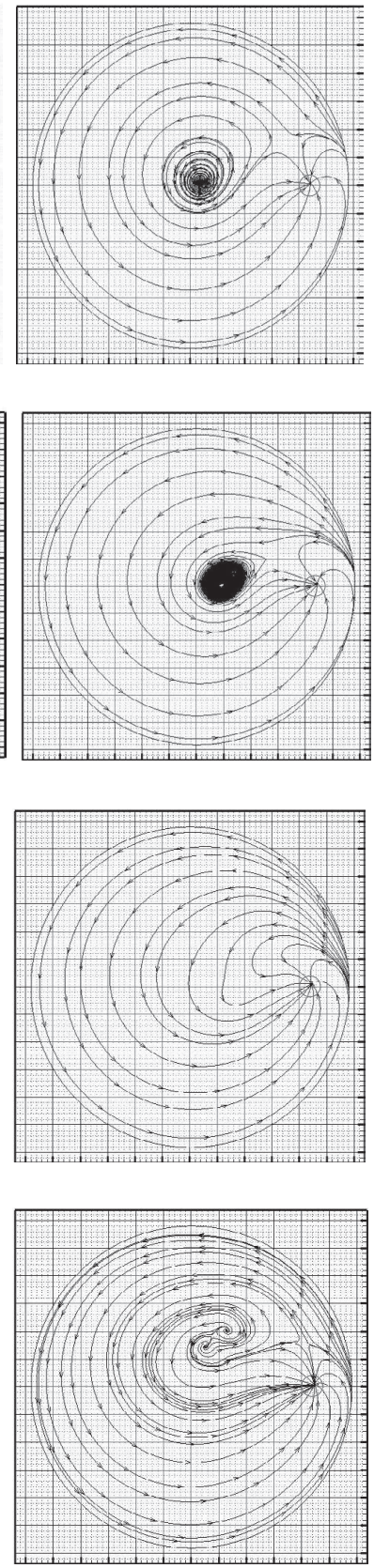

Fig. 4. Stream diagram for different eccentricities at $0.05 \mathrm{~m}$ at different times, $\bigcirc$-nozzle: (a) eccentricity is 0 ; (b) eccentricity is 0.25 ; (c) eccentricity is 0.75 .

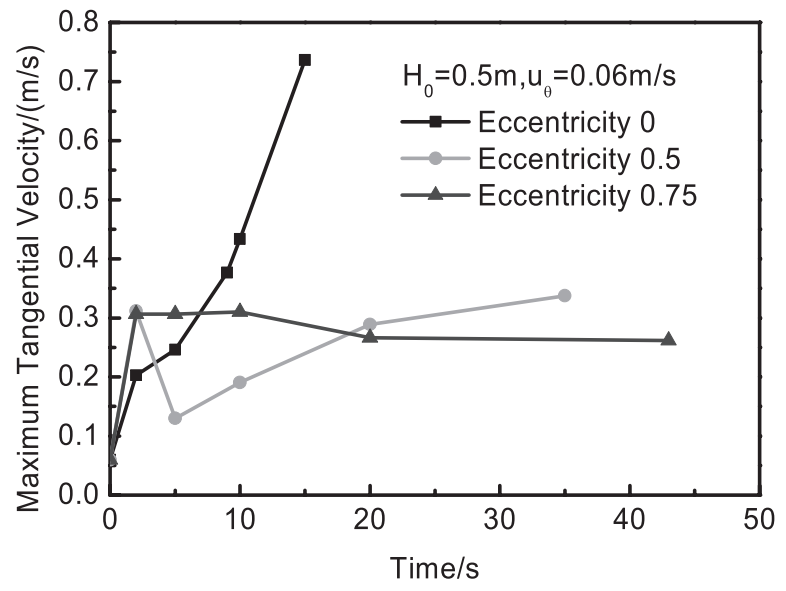

Fig. 5. Distribution of tangential velocity vs. time at $0.05 \mathrm{~m}$. the nozzle is located in the center of ladle bottom. But when the nozzle is eccentric, the tangential velocity first increases rapidly over $0-2 \mathrm{~s}$ after the nozzle is opened, then it decreases, and finally it increases slowly or stays constant. The tangential velocity decreases with increasing eccentricity. The tangential velocity increases rapidly at first because the molten steel flowing out of the nozzle enhances the tangential force acting on the steel flowing rotationally around the ladle center. But the center of the vortex can move towards the nozzle over time, which suppresses the development of the vortex and eventually decreases its critical height.

Figure 6 shows that the maximum tangential velocity in every plane almost decreases at the higher positions. Thus, the tangential velocity is larger at the bottom of ladle. 


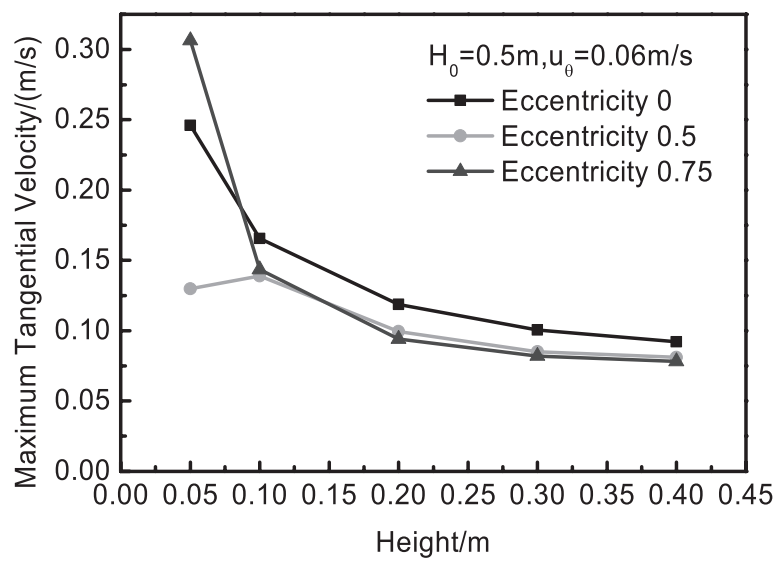

Fig. 6. Distribution of tangential velocity $v s$. height at $5 \mathrm{~s}$.

Hence, the vortex critical height can be decreased by increasing the eccentricity of the nozzle, which can be selected according to various factors. The body of the ladle can be inclined during steel teeming much like the electric furnace. This can shorten the time of steel teeming and reduce the amount of residual molten steel due to slag entrainment. However, an inclined ladle changes tremendously the temperature of the liner wall, reducing its lifetime. The ladle may be also made into the inclined bottom, then increasing eccentricity can decrease the critical height of vortex and reduce amount of residual molten steel. ${ }^{3)}$

\subsection{Effect of Nozzle Diameter on Vortex Formation}

Nozzle diameters were set as $0.06 \mathrm{~m}, 0.0765 \mathrm{~m}$, and 0.1 m. For an eccentricity of 0.5 , initial liquid level $H_{0}=0.5 \mathrm{~m}$, and initial tangential velocity $u_{\theta}=0.06 \mathrm{~m} / \mathrm{s}$, molten steel initially rotates anticlockwise around the center of ladle. Simulation results for steel teeming are as follows.

Figure 7 shows that the vortex critical height changes with the different nozzle diameter when eccentricities are 0 and 0.5 . When the eccentricity is 0 , the critical height decreases a little with the nozzle diameter increasing. The critical height of vortex is almost between $0.28 \mathrm{~m}$ and 0.3 $\mathrm{m}$. The vortex formation time is shortened with increasing nozzle diameter. That is because when the nozzle is central, the nozzle diameter has a little effect on the critical height but has a large effect on the flow rate out of the nozzle. The larger nozzle diameter is the more quickly liquid level descends and the shorter the vortex formation time is. When the eccentricity is 0.5 the critical height increases significantly as the nozzle diameter increases. The critical height of vortex is 0.082 when the nozzle diameter is $0.06 \mathrm{~m}$, but it is $0.171 \mathrm{~m}$ when the nozzle diameter is $0.1 \mathrm{~m}$. And the time for vortex extension to the nozzle is prolonged with decreasing the nozzle diameter regardless of the eccentricity change. Vortex movement occurs as discussed above. The movement of the vortex center slows with decreasing nozzle diameter when the nozzle position is eccentric. So the flow rate of molten steel can be reduced with proper adjustment of the nozzle valve, which is equivalent to reducing the nozzle diameter. The vortex critical height can thus be decreased effectively.

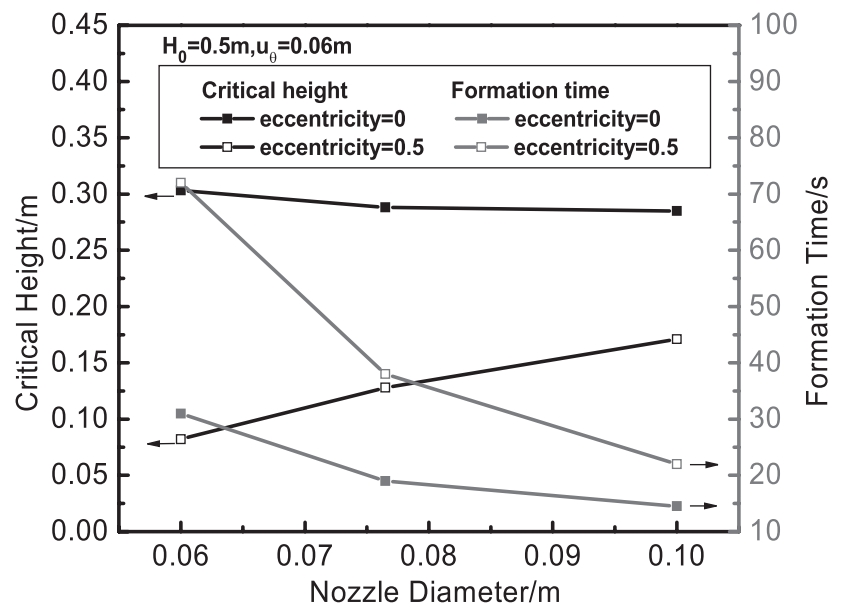

Fig. 7. Critical height of vortex and formation time vs. nozzle diameter.

\subsection{Effects of Molten Steel Physical Properties on Vor- tex Formation}

Molten steel, water, petrol, mercury and glycerol are chosen as distinctly different fluids to demonstrate how vortex formation is affected by physical properties. Their physical parameters are summarized in Table 1 . The nozzle eccentricities are 0 and 0.5 , initial liquid level $H_{0}=0.5 \mathrm{~m}$, and initial tangential velocity $u_{\theta}=0.06 \mathrm{~m} / \mathrm{s}$, respectively.

The vortex critical height is related to $R_{e}$, where $R_{e}$ is the Reynolds Number. The relation is derived by the Buckingham $\pi$ theorem.

$$
H_{\text {critical }}=f\left(H_{0}, d, D, u_{\theta}, \rho, \mu, \sigma, \varepsilon, g\right)
$$

Where $H_{\text {critical }}$ is critical height, $d$ is diameter of nozzle, $D$ is diameter of ladle, $\rho$ is density, $\mu$ is viscosity, $\sigma$ is surface tension, $\varepsilon$ is eccentricity, $g$ is acceleration of gravity. $H_{0}, \rho$ and $g$ are used as the common variables, seven $\pi$ groups can be obtained:

$$
\begin{aligned}
& \pi_{1}=H_{\text {critical }} / H_{0} \\
& \pi_{2}=d / H_{0} \\
& \pi_{3}=D / H_{0} \\
& \pi_{4}=u_{\theta} / \sqrt{g H_{0}} \\
& \pi_{5}=\mu /\left(\rho \sqrt{H_{0}^{3} g}\right) \\
& \pi_{6}=\sigma /\left(\rho g H_{0}^{2}\right) \\
& \pi_{7}=\varepsilon
\end{aligned}
$$

$\pi_{2}$ and $\pi_{3}$ are geometric similarity ratios, which combined into one, namely, $\pi_{2} / \pi_{3}=d / D$. And $\sqrt{g H_{0}} \approx \sqrt{2 g H_{0}} \approx V_{\text {out }}{ }^{13)} V_{\text {out }}$ is velocity of outlet. So $\pi_{5}=\mu /\left(\rho \sqrt{H_{0}^{3} g}\right) \approx \mu /\left(\rho V_{\text {out }} H_{0}\right)=$ $1 / \operatorname{Re}, \pi_{7}=\sigma /\left(\rho g H_{0}^{2}\right) \approx \sigma /\left(\rho V_{\text {out }}^{2} H_{0}\right)=1 / W e, W_{e}$ is the Weber Number. So Eq. (10) is obtained. $\pi_{6}$ and $\pi_{7}$ represent the physical properties. $W_{e} \approx(7000 \times 9.81 \times 0.5 \times 0.5) / 1.6=10730>$ 120 , so surface tension can be ignored ${ }^{21)}$ (Surface tension of 
steel is the smallest of the five.). Thus the effect of physical property can be studied by Reynolds number $R_{e}$.

$$
H_{\text {critical }} / H_{0}=f\left(d / D, u_{\theta} / \sqrt{g H_{0}}, 1 / W e, 1 / \mathrm{Re}, \varepsilon\right) \ldots
$$

Figure 8 shows the changes between the critical height, formation time and the physical properties such as viscosity and density when the eccentricities are 0 and 0.5 . Reynolds Number $R_{e}$ is the ratio of inertial force and viscosity force $\left(\operatorname{Re}=1 / \pi_{5}\right.$ in Fig. 8). The critical height increases with increasing $R_{e}$ when the eccentricity is 0 . However, the critical height decreases except for glycerol with increasing $R_{e}$ when the nozzle position is eccentric (the eccentricity is $0.5)$. This is because viscosity force can weaken the inertial force caused by the initial disturbance and promote the movement of vortex core. The phenomenon of glycerol is unique, because of the high viscosity of glycerol. So high viscosity not only weakens the inertial force caused by initial disturbance but also suppresses the evolution of vortex. Therefore, the critical height of glycerol is lower than the others regardless of eccentricity of either 0 or 0.5 . On the contrary, the vortex forms more quickly in the eccentric nozzle than that in the central nozzle when the fluid is glycerol because of the high viscosity. The change of formation time is opposite to that of critical height regardless of the nozzle position that is central or eccentric.

From the above, when the nozzle position is central, the critical height only increases a little with decreasing nozzle diameter. When the nozzle position is eccentric, the critical height increases significantly with increasing nozzle diameter and with decreasing eccentricity. But the physical property except for glycerol only has a little effect regardless of central nozzle or eccentric nozzle. And the changes of formation time almost are opposite to those of critical height.

\section{Formula for Predicting the Vortex Critical Height}

The ladle diameter and the initial liquid level can also affect the vortex critical height during steel teeming. The formula for the critical height is obtained through the analysis of steel teeming under different conditions. For different

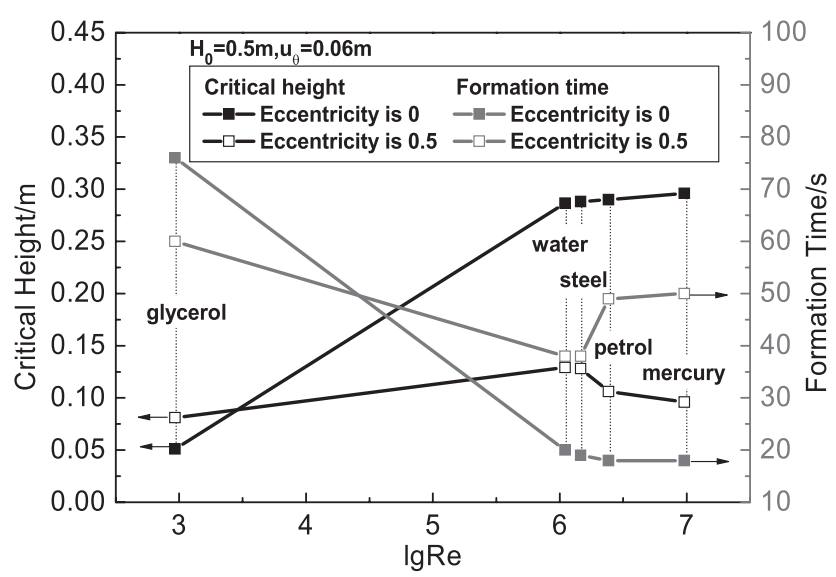

Fig. 8. Vortex critical height and formation time vs. physical properties of fluids. ladle structures, different steel grades or different initial conditions, the vortex critical height can be estimated. So this formula is helpful to minimize the vortex. The formula is considered as two different cases because the changes of critical height are different with central nozzle and with eccentric nozzle. Because surface tension can be ignored for steels, Eq. (10) can be written as Eq. (11).

$$
H_{\text {critical }} / H_{0}=f\left(d / D, u_{\theta} / \sqrt{g H_{0}}, 1 / \mathrm{Re}, \varepsilon\right) \ldots
$$

Then,

$$
\begin{aligned}
& H_{\text {critical }} / H_{0}=a \cdot(d / D)^{b} \cdot\left(u_{\theta} / \sqrt{g H_{0}}\right)^{c} \cdot(1 / \mathrm{Re})^{f} \cdot\left(e^{\varepsilon}\right)^{k} \\
& \ldots \ldots \ldots \ldots \ldots \ldots \ldots \ldots \ldots \ldots \ldots \ldots \ldots \ldots \ldots \ldots \ldots \ldots \ldots \ldots \ldots \ldots \ldots \ldots \ldots \\
& \lg \left(H_{\text {critical }} / H_{0}\right)= a+b \cdot \lg (d / D)+c \cdot \lg \left(u_{\theta} / \sqrt{g H_{0}}\right) \\
&+f \cdot \lg (1 / \mathrm{Re})+k \cdot \lg \left(e^{\varepsilon}\right)
\end{aligned}
$$

Where $a$ is the constant term and $b, c, f, k$ are coefficients. $a$ and $b, c, f, k$ can be determined by SPSS (Statistical Product and Service Solutions) statistical software. Table 2 shows the results including the physical property term $\lg (1 / \mathrm{Re})$ in Eq. (13). In Table 2, adjusted $\mathrm{R}$ square represents the fitting effect. The higher value of adjusted $\mathrm{R}$ square (close to 1 ) means the better fitting. The $\mathrm{t}$ test is used for testing the significance of the regression coefficient. The $t$ value is the statistics. Sig. represents the significance level of the discrepancy, and its range is less than 0.05 , namely, Sig. $<0.05$. Partial correlation represents the degree of correlation between independent and dependent variables. The higher absolute value of partial correlation (close to 1) means the better correlation. ${ }^{22)}$ In Table 2, the Sig. value of variable $\lg (1 / \mathrm{Re})$ is 0.123 when the nozzle position is central and it is 0.983 when the nozzle position is eccentric. The partial correlations are -0.520 and 0.010 respectively. The Sig. values of variable $\lg (1 / \mathrm{Re})$ are greatest and exceeding 0.05 . The partial correlations of variable $\lg (1 / \mathrm{Re})$ are also far away from 1 . So the variable $\lg (1 / \operatorname{Re})$ has a little effect on the dependent variable $\lg \left(H_{\text {critical }} / H_{0}\right)$. And their correlation is not good. Thus the term of physical property parameter $(\lg (1 / \operatorname{Re}))$ shouldn't be considered in Eq. (13).

Table 3 shows the result excluding the effect of physical property term $\lg (1 / \mathrm{Re})$ in Eq. (13). In Table 3, all the values of Sig. are less than 0.05. And partial correlations of all the independent variables are close to 1 . Thus the results of Table 3 have a good correlation and a good fitting effect between the independent variables and dependent ones. So the formula of critical height is finally summarized in Eq. (14). 
Table 2. Results of linear fit including the term of physical property parameter $(\lg (1 / \operatorname{Re}))$.

\begin{tabular}{|c|c|c|c|c|c|c|c|}
\hline & Variables & $\begin{array}{l}\text { Unstandardized } \\
\text { coefficients }\end{array}$ & Std. Error & $\begin{array}{l}\text { Standardized } \\
\text { coefficients }\end{array}$ & $\mathrm{t}$ test & Sig. & $\begin{array}{l}\text { Partial } \\
\text { correlation. }\end{array}$ \\
\hline \multirow{4}{*}{$\begin{array}{l}\text { Central } \\
\text { nozzle }\end{array}$} & $\lg (d / D)$ & -0.458 & 0.209 & -1.220 & -2.196 & 0.059 & -0.613 \\
\hline & $\lg \left(u_{\theta} / \sqrt{g H_{0}}\right)$ & 0.744 & 0.043 & 3.001 & 17.366 & 0.000 & 0.987 \\
\hline & $\lg (1 / \operatorname{Re})$ & -0.063 & 0.037 & -0.887 & -0.887 & 0.123 & -0.520 \\
\hline & \multicolumn{7}{|c|}{ Adjusted R square $=0.991$, dependent variable: $\lg \left(H_{\text {critical }} / H_{0}\right)$} \\
\hline \multirow{4}{*}{$\begin{array}{c}\text { Eccentric } \\
\text { nozzle }\end{array}$} & $\lg (d / D)$ & 0.813 & 0.312 & 1.359 & 2.605 & 0.048 & 0.759 \\
\hline & $\lg \left(u_{\theta} / \sqrt{g H_{0}}\right)$ & 0.038 & 0.008 & 0.199 & 4.670 & 0.005 & 0.902 \\
\hline & $\lg (1 / \operatorname{Re})$ & 0.001 & 0.061 & 0.012 & 0.022 & 0.983 & 0.010 \\
\hline & $\lg (\varepsilon)$ & -1.305 & 0.411 & 0.530 & -3.178 & 0.025 & -0.818 \\
\hline
\end{tabular}

Table 3. Results of linear fit excluding the term of physical property parameter $(\lg (1 / \operatorname{Re}))$.

\begin{tabular}{cccccccc}
\hline & Variables & $\begin{array}{c}\text { Unstandardized } \\
\text { coefficients }\end{array}$ & Std. Error & $\begin{array}{c}\text { Standardized } \\
\text { coefficients }\end{array}$ & t test & Sig. & $\begin{array}{c}\text { Partial } \\
\text { correlation. }\end{array}$ \\
\hline \multirow{2}{*}{$\begin{array}{c}\text { Central } \\
\text { nozzle }\end{array}$} & $\lg (d / D)$ & -0.800 & 0.071 & -2.131 & -11.207 & 0.000 & -0.966 \\
& $\lg \left(u_{\theta} / \sqrt{g H_{0}}\right)$ & 0.750 & 0.047 & 3.027 & 15.920 & 0.000 & 0.983 \\
\hline \multirow{2}{*}{$\begin{array}{c}\text { Edjusted R square }=0.988, \text { dependent variable: } \lg \left(H_{\text {critical }} / H_{0}\right) \\
\text { nozzle }\end{array}$} & $\lg (d / D)$ & 0.819 & 0.087 & 1.370 & 9.379 & 0.000 & 0.968 \\
& $\lg \left(u_{\theta} / \sqrt{g H_{0}}\right)$ & 0.038 & 0.007 & 0.199 & 5.137 & 0.002 & 0.903 \\
& $\lg (\varepsilon)$ & -1.302 & 0.361 & -0.529 & 3.603 & 0.011 & -0.827 \\
\hline
\end{tabular}

$$
\left\{\begin{aligned}
\lg \left(H_{\text {critical }} / H_{0}\right) & =-0.800 \lg (d / D) \\
& +0.75 \lg \left(u_{\theta} / \sqrt{g H_{0}}\right), \quad \varepsilon=0 \\
\lg \left(H_{\text {critical }} / H_{0}\right) & =0.819 \lg (d / D)+0.038 \lg \left(u_{\theta} / \sqrt{g H_{0}}\right) \\
& -1.302 \lg (\varepsilon), \quad \varepsilon \neq 0
\end{aligned}\right.
$$

Figure 9 shows the comparison between the experimental results $^{13,23)}$ and the formula results. In the experiments, the fluid is water and the slag isn't considered. The initial liquid level $H_{0}$ is $0.995 \mathrm{~m}, 0.425 \mathrm{~m}$ and $0.1 \mathrm{~m}$ in the experiments at different eccentricities when the conditions are $(D=1.16$ $m, d=0.0356 m),(D=0.495 m, d=0.014 m)$ in Ref. 13) and $(D=0.2 m, d=0.005 m)$ in Ref. 23), respectively. And the initial tangential velocities and the critical heights of vortex are measured. The formula results are determined by Eq. (14). The max error between experimental results and formula results is $0.0594 \mathrm{~m}$ and the min error is $0.0177 \mathrm{~m}$ when the nozzle position is central. The max error is 0.0299 $\mathrm{m}$ and the min error is $0.0038 \mathrm{~m}$ when the nozzle position is eccentric. From Fig. 9, it can be concluded that the experimental and the calculated results have similar tendency. In practice, the critical height is almost unchanged when the initial tangential velocity exceeds a certain value. So it should be noted that when the critical height determined by Eq. (14) exceeds the initial liquid level, it can be considered

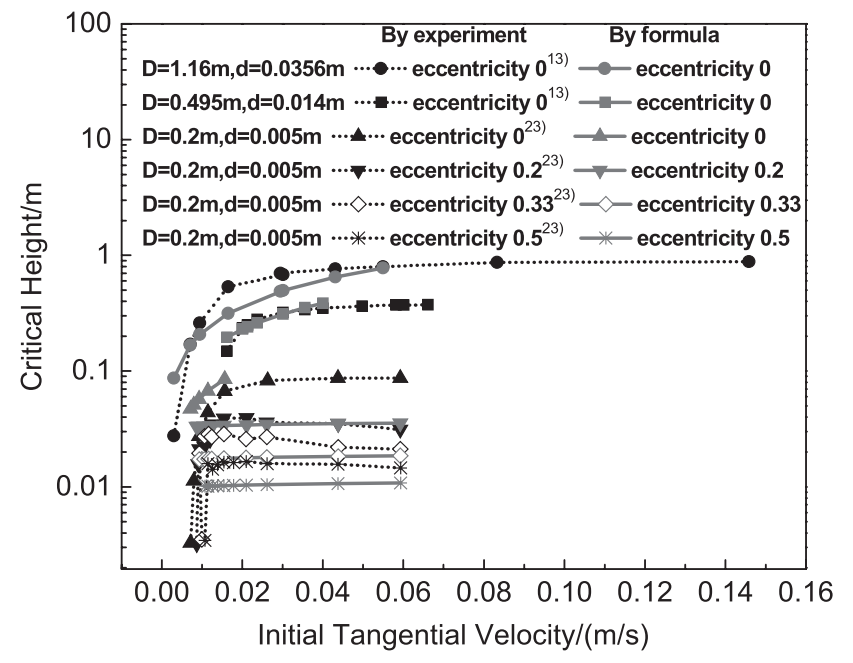

Fig. 9. Comparison between the experimental results ${ }^{13,23)}$ and the formula results.

as the initial liquid level approximatively.

In summary, the formula allows us to predict the vortex critical height formation under different conditions. The vortex can be suppressed by the following measures. To reduce residual movement, molten steel can be rested for a long time in the ladle. An appropriate nozzle eccentricity is applied and the bottom ladle is inclined. Meanwhile, 
the nozzle valve can be adjusted accordingly as the vortex forms. More effective suppression way of vortexes will require further research.

\section{Conclusions}

By simulating steel teeming under different conditions, factors affecting vortex formation were analyzed and a formula for determining the vortex critical height was derived. The following conclusions can be written.

(1) The Coriolis force has little effect on vortexes during steel teeming. Instead, the initial tangential disturbance in the molten steel before teeming is the main factor for vortex formation.

(2) The vortex center can move towards the nozzle when the nozzle is eccentric. This movement decreases the tangential velocity and the vortex critical height.

(3) Initial tangential velocity, nozzle diameter, eccentricity and liquid physical property have significant effects on the vortex formation. The effect of physical property is small.

(4) Without considering the thermal convection, the formula to predict the vortex critical height was developed. When the nozzle position is central, the critical height is related to initial tangential velocity and the ratio between nozzle diameter and ladle diameter. When the nozzle position is eccentric, the critical height is also related to eccentricity.

\section{Acknowledgments}

This work was supported by the National Natural Science Foundation of China (Grant No. U1560207), the Open Foundation of State Key Laboratory of Advanced Metallurgy of University of Science and Technology Beijing (KF12-07), and the 111 Project (No. B07015).

\section{REFERENCES}

1) Y. Huang, S. F. Ye, T. S. Su and M. M. Li: Jiangxi Metall., 19 (1999), 1.

2) Q. Wang, S. P. He, Y. M. He, W. M. Chen and J. C. Li: Iron Steel, 42 (2007), 32

3) G. M. Mazzaferro, M. Piva, S. P. Ferro, P. Bissio, M. Iglesias, A Calvo and M. B. Goldschmit: Ironmaking Steelmaking, 31 (2004), 503.

4) E. N. D. C. Andrade: Proc. R.. Inst. London, 29 (1936), 320.

5) A. H. Shapiro: Nature, 196 (1962), 1080

6) L. Trefethen, R. W. Bilger, P. T. Fink, R. E. Luxton and R. I. Tanner: Nature, 207 (1965), 1084

7) K. B. Haugen and P. A. Tyvand: Phys. Fluids, 15 (2003), 742.

8) J. W. Suh, J. Park, H. Kim and Z. H. Lee: ISIJ Int., 41 (2001), 689.

9) R. Lin, Z. G. Yan and J. K. Yu: J. Northeastern Univ. (Nat. Sci.), 31 (2010), 1287.

10) P. Hammerschmid, K. A. Tacke, H. Popper, L. Weber and K. Schwerdtfeger: Ironmaking Steelmaking, 11 (1984), 322.

11) R. D. Morales, O. Davila-Maldonado, I. Calderon and K. MoralesHiga: ISIJ Int., 53 (2013), 782

12) R. Lin, Z. G. Yan, T. Liu and J. K. Yu: Chin. J. Process Eng., 10 (2010), 655.

13) R. Sankaranarayanan and R. I. L. Guthrie: Ironmaking Steelmaking, 29 (2002), 147.

14) Y. Huang, S. F. Ye, Y. P. Tao, M. M. Li and Z. M. Huang: J. Iron Steel Res. Int., 7 (1995), 9.

15) D. Sucker, J. Reinecke and H. Hage-Jewainski: Stahl Eisen, 105 (1985), 765 .

16) Y. Z. Zhao, Z. L. Gu, Y. Z. Yu and X. Feng: Shuili Xubao, 12 (2002), 1.

17) K. Kuwana, M. I. Hassan, P. K. Singh, K. Saito and J. Nakagawa: Mater. Manuf. Process., 23 (2008), 407.

18) O. Davila, R. D. Morales and L. Garcia-Demedices: Metall. Mater. Trans. B, 37B (2006), 71.

19) H. X. Li, Q. Wang, J. W. Jiang, H. Lei, Z. C. Guo and J. C. He: ISIJ Int., 54 (2014), 1592.

20) Y. Z. Wang and Y. Zhang: New Continuous Casting Technology and Equipment, Metallurgical Industry Press, Beijing, (2007), 57.

21) A. K. Jain, K. G. Ranga and R. J. Garde: J. Hydraul. Div.-ASCE, 104 (1978), 1429.

22) L. Feng: Principle of Regression Analysis Method and SPSS Actual Practice, China Financial Publishing House, Beijing, (2004), 114.

23) M. Piva, M. Iglesias, P. Bissio and A. Calvo: Physica A, 329 (2003), 1. 